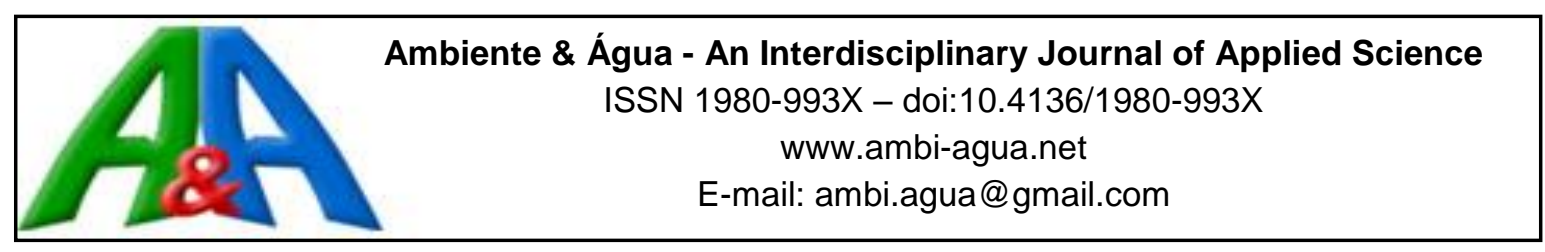

\title{
Secas e seus impactos no município de Boqueirão, PB, Brasil
}

\author{
doi:10.4136/ambi-agua.2004
}

Received: 13 Sep. 2016; Accepted: 18 Jan. 2017

\author{
André Aires de Farias*; Francisco de Assis Salviano de Sousa; \\ João Miguel Moraes Neto; Anailson de Sousa Alves \\ Universidade Federal de Campina Grande (UFCG), Campina Grande, PB, Brasil \\ Centro de Tecnologia e Recursos Naturais (CTRN) \\ *Autor correspondente: e-mail: andreaires61@ @otmail.com, \\ fsouza2011@gmail.com,moraes@deag.ufcg.edu.br, anailson_agro@hotmail.com
}

\section{RESUMO}

Secas são fenômenos naturais que ocorrem quando a precipitação é inferior às médias pluviométricas de uma determinada região. Contudo, não há um consenso para se definir o real significado do tema, em razão de que as variáveis hidrometeorológicas e socioeconômicas são diferentes nas diversas regiões do mundo. Objetivou-se caracterizar e analisar as secas e seus impactos no município de Boqueirão - PB. Para se identificar as secas foi utilizado o Índice Padronizado de Precipitação (IPP) com dados de 1963-2014. Com relação aos impactos, foram analisados dados referentes à agricultura (de 2011, 2012 e 2013), dados da pecuária e de produtos agropecuários produzidos nos anos de 2011, 2012, 2013 e 2014. As secas mais graves no município de Boqueirão ocorreram nos anos de 1980-1982, 1998-2000 e 2012-2013. Destas, a mais impactante foi a de 1998-2000. Essa seca reduziu drasticamente a produção agropecuária e o abastecimento de água da região. Os impactos mais intensos durante a seca 2012-2014 ocorreram em 2012 e 2013. As culturas agrícolas temporárias foram mais impactadas do que as permanentes. Isso ocorreu porque a maioria das permanentes eram irrigadas, diferente das temporárias. A maior redução de animais também ocorreu durante 2012 e 2013, com uma relação direta entre precipitação e o efetivo dos rebanhos. Não houve redução do valor da produção em função das secas.

Palavras-chave: déficit hídrico, índices de seca, risco climático.

\section{Droughts and their impacts on the municipality of Boqueirão, PB, Brazil}

\begin{abstract}
Droughts are natural phenomena that occur when precipitation falls below average in a given region. However, no consensus exists regarding the definition of this term due to differing hydro meteorological and socioeconomic variables in various regions of the world. In this work, we identified and analyzed droughts and their impacts on the municipality of Boqueirão - PB. We used the Standardized Precipitation Index (SPI) to identify droughts. Regarding impacts, we analyzed agricultural data from 2011, 2012 and 2013 as well as data relating to livestock and agricultural products produced in 2011, 2012, 2013 and 2014. The most severe droughts in Boqueirão municipality occurred in the years 1980-1982, 1998-2000 and 2012-2013. The greatest impact was observed in 1998-2000. The droughts have drastically reduced agriculture
\end{abstract}


production and water supply in the region. The most severe impacts during the drought of 20122014 occurred in 2012 and 2013. Temporary crops were more affected than the permanent ones. This was because most of the permanent crops were irrigated, unlike the temporary ones. The greatest reduction of animals also occurred during 2012 and 2013, with a direct relationship between precipitation and herd populations. The droughts caused no reduction in the value of production.

Keywords: climate risk, drought indices, water deficit.

\section{INTRODUÇÃO}

A seca é um fenômeno natural presente em todas as regiões do mundo. De todos os desastres naturais ocorridos, a seca é responsável por $22 \%$ dos gastos, $33 \%$ do número de pessoas afetadas e 3\% do número de mortos. A seca é o mais complexo de todos os fenômenos naturais, afetando um maior número de pessoas do que qualquer outro (Wilhite et al., 2007). Diferenças nas variáveis hidrometeorológicas e em fatores socioeconômicos, bem como a natureza estocástica da demanda de água em diferentes regiões ao redor do mundo, tornaramse um obstáculo para ter uma definição precisa de seca. Mesmo assim, a Organização Meteorológica Mundial (WMO, 1986) define seca como uma deficiência na precipitação. Já a Convenção das Nações Unidas de Combate à Desertificação e à Seca (UNCCD, 1994) define como um fenômeno que ocorre naturalmente quando a precipitação foi significativamente abaixo dos níveis normais registrados, provocando um sério desequilíbrio hídrico que afeta negativamente o meio urbano e rural.

A seca é uma condição natural que causa uma ampla gama de impactos sociais, econômicos e ambientais, desde a redução da produção agrícola até restrições na utilização de água nas residências. Secas de longa duração ou eventos de secas severas frequentes em regiões áridas e semiáridas podem levar a consequências ainda mais devastadoras, como a redução do abastecimento de alimentos e a desertificação (Mishra e Singh, 2010). Sistemas de monitoramento capazes de detectar e mapear secas em grandes escalas espaciais e com continuidade temporal são essenciais para avaliar a gravidade e extensão da seca e atenuar os seus impactos (Li e Rodell, 2015).

As características da precipitação são componentes muito utilizados para a redução dos riscos climáticos (Bordi et al., 2009). Nos últimos anos, o Índice padronizado de precipitação (IPP) (McKee et al., 1993) tem sido amplamente utilizado e se destacado sobre os outros índices (Guttman, 1999) e (Keyantash e Dracup, 2002). Assim, o IPP foi aceito pela WMO como o índice mais efetivo para o monitoramento de secas e redução de riscos (Hayes et al., 2011).

Além disso, o IPP foi projetado para quantificar o déficit ou excesso de precipitação em múltiplas escalas de tempo. As mais curtas são usadas para caracterizar as secas meteorológicas, estas são importantes para as atividades agrícolas, pois a umidade do solo tem uma resposta rápida em relação às anomalias de precipitação. Escalas de tempo mais longas são usadas para monitorar, principalmente, as secas hidrológicas, pois estas são de grande importância no abastecimento das fontes superficiais e subterrâneas (Sirdas e Sen, 2003).

Vários estudos analisaram a evolução espaço-temporal do IPP em diferentes escalas de tempo e em diversas regiões, entre eles Lloyd-Huges e Saunders (2002), Sonmez et al. (2005), Vicente-Serrano (2006), Livada e Assimakopoulos (2007) e Zhai et al. (2010). Outras pesquisas identificaram tendências de períodos secos e chuvosos nas séries temporais analisadas ao redor do mundo, Bordi et al. (2009), Santos et al. (2010) e Fischer et al. (2013).

No Brasil, Teixeira et al. (2013) observaram que dos 1164 meses analisados em Bagé, RS, Brasil, quanto aos valores de IPP, 6,8\% foram classificados como eventos de seca severa e extrema. Farias et al. (2014) em pesquisa no município de Taperoá-PB, observaram que houve 
uma grande variabilidade temporal das séries pluviométricas analisadas, o município apresentou meses extremamente secos seguidos de meses úmidos ou normais. Os IPPs detectaram, segundo a intensidade média, secas severas e extremas. Embora não esteja no artigo, a categoria de seca moderada aconteceu com maior frequência.

Data de 1583 o primeiro relato de uma seca no Nordeste do Brasil (NEB), feito pelo Padre Fernão Cardin, (BRASIL, 1981), porém é consenso que o fenômeno seca é tão antigo quanto o surgimento do ser humano na Terra. Então, os seguintes questionamentos são levantados para o município de Boqueirão-PB: Em que anos ocorreram secas mais graves na série 1963-2014? Quais foram os impactos da seca de 2012-2014? Diante do que foi apresentado, objetivou-se identificar e analisar as secas e seus impactos no município de Boqueirão, PB, Brasil.

\section{MATERIAL E MÉTODOS}

A área de estudo compreende o município de Boqueirão-PB, localizado na Mesorregião da Borborema e na Microrregião do Cariri Oriental (Figura 1).

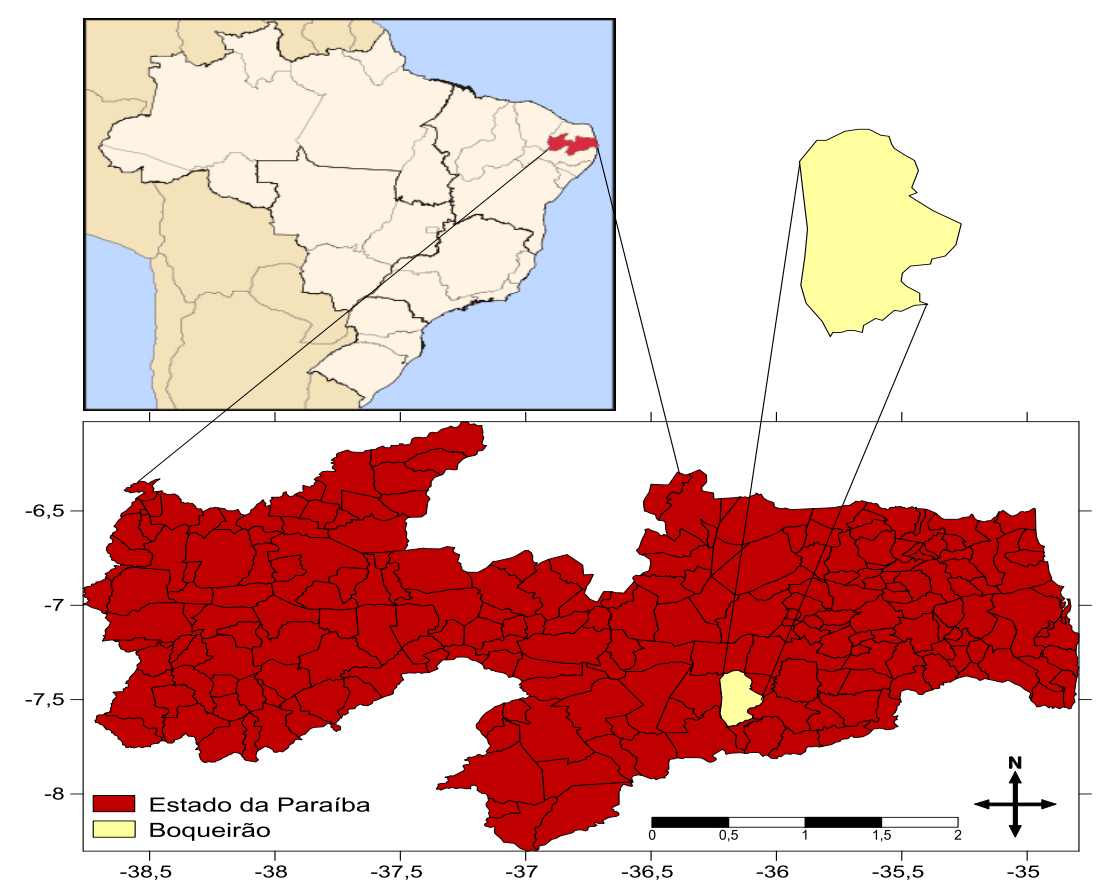

Figura 1. Localização geográfica do município de Boqueirão-PB.

Os dados pluviométricos foram obtidos na Agência Executiva de Gestão das Águas do Estado da Paraíba (AESA). Foram utilizados dados de totais mensais precipitados para o período de 1963-2014.

A caracterização do regime de precipitação pluvial foi realizada por meio do ajuste das séries empíricas à distribuição gama. A função distribuição de probabilidade gama é visualizada na Equação 1.

$$
g(x)=\frac{1}{\beta^{\alpha} \Gamma(\alpha)} x^{\alpha-1} e^{-x / \beta}
$$

em que:

$\alpha>0=$ parâmetro de forma da distribuição gama;

$\beta>0=$ parâmetro de escala da distribuição gama; 


$$
\begin{aligned}
& \chi>0=\text { total de precipitação; e } \\
& \Gamma(\alpha)=\text { função gama. }
\end{aligned}
$$

Para estimativa dos parâmetros $\alpha$ e $\beta$, utilizaram-se as soluções de máxima verossimilhança (Equações 2, 3 e 4).

$$
\begin{aligned}
& \alpha=\frac{1}{4 A}\left(1+\sqrt{\left.1+\frac{4 A}{3}\right)}\right. \\
& A=\ln (\bar{x})-\frac{\sum_{i}^{n} x_{i}}{n} \\
& \beta=\frac{\bar{x}}{\alpha}
\end{aligned}
$$

em que:

$$
\begin{aligned}
& \bar{x}=\text { média aritmética da precipitação pluvial }(\mathrm{mm}) \\
& \ln =\text { logaritmo neperiano; e } \\
& \mathrm{n}=\text { número de observações da amostra. }
\end{aligned}
$$

Após a estimativa de $\mathrm{g}(\mathrm{x})$ para as séries de precipitações investigadas, o IPP pôde ser calculado através da Equação 5.

$$
H(x)=q+(1-q) G(x)
$$

em que:

$H(x)=$ distribuição de probabilidade cumulativa;

$\mathrm{q}=$ probabilidade de ocorrência de valores nulos (zeros); e

$\mathrm{G}(\mathrm{x})=$ distribuição cumulativa teórica.

Se $\mathrm{m}$ for o número de zeros numa série de precipitação, então $q=\mathrm{m} / \mathrm{n}$. em que:

m - número de observações com chuva igual a zero; e

$\mathrm{n}$ - número de observações com chuva maior do que zero.

$\mathrm{H}(\mathrm{x})$ foi então transformada em uma variável normal (valor final do IPP) por meio das equações desenvolvidas por Abramowitz e Stegun (1965). A relação entre as distribuições de probabilidade gama e normal é apresentada nas Equações 6, 7, 8 e 9.

$$
\begin{aligned}
& Z=S P I=-\left(t-\frac{c_{0}+c_{1} t+c_{2} t^{2}}{1+d_{1} t+d_{2} t^{2}+d_{3} t^{3}}\right) \text { Para } 0<H(x) \leq 0,5 \\
& Z=S P I=+\left(t-\frac{c_{0}+c_{1} t+c_{2} t^{2}}{1+d_{1} t+d_{2} t^{2}+d_{3} t^{3}}\right) \text { Para } 0,5<H(x) \leq 1,0
\end{aligned}
$$

em que:

$$
\mathrm{c} 0=2,515 ; \mathrm{c} 1=0,803 ; \mathrm{c} 2=0,010 ; \mathrm{d} 1=1,433 ; \mathrm{d} 2=0,189 ; \mathrm{e} \mathrm{d} 3=0,001
$$

\section{IPABH}




$$
\begin{gathered}
t=\sqrt{\ln \left(\frac{1}{(H(x))^{2}}\right)} \text { Para } 0<H(x) \leq 0,5 \\
\mathrm{e}_{t}=\sqrt{\ln \left(\frac{1}{(1-H(x))^{2}}\right)} \text { Para } 0,5<H(x) \leq 1,0
\end{gathered}
$$

Os valores do IPP com suas categorias estão disponíveis na Tabela 1. Em função de serem mais graves, analisou-se apenas as secas severas e extremas, pois são estas que causam os impactos sociais, econômicos e ambientais mais intensos.

Tabela 1. Valores do IPP e categorias de chuvas e de secas.

\begin{tabular}{cl}
\hline Valores do IPP & \multicolumn{1}{c}{ Categoria } \\
\hline$\geq 2,00$ & Chuva extrema \\
1,50 a 1,99 & Chuva severa \\
1,00 a 1,49 & Chuva moderada \\
0 a 0,99 & Chuva fraca \\
0 a $-0,99$ & Seca fraca \\
$-1,00$ a $-1,49$ & Seca moderada \\
$-1,50$ a $-1,99$ & Seca severa \\
$\leq-2,00$ & Seca extrema \\
\hline
\end{tabular}

Fonte: Mckee et al. (1993).

Para análise dos impactos foram utilizados dados obtidos no Instituto Brasileiro de Geografia e Estatística (IBGE, 2015). Na agricultura, foram analisados: Área plantada (ha), área colhida (ha), quantidade produzida (ton), rendimento médio ( $\mathrm{kg} / \mathrm{ha}$ ) e valor da produção (R\$) da banana, caju, coco, goiaba, laranja, limão, mamão, maracujá, manga, algodão herbáceo, batata-doce, cebola, fava, feijão, milho e tomate dos anos de 2011, 2012 e 2013 . O ano de 2014 não foi incluído porque os dados ainda não estavam disponíveis.

Na pecuária foi analisado o efetivo dos rebanhos de asininos, bovinos, caprinos, equinos, galos e galinhas; muares, ovinos e suínos dos anos de 2011, 2012, 2013 e 2014.

Com relação aos produtos agropecuários, foram utilizadas as variáveis: leite de vaca (quantidade), leite de vaca (valor da produção R\$), ovos de galinha (quantidade) e ovos de galinha (valor da produção R\$) dos anos de 2011, 2012, 2013 e 2014.

A opção de analisar apenas os impactos da última seca foi devido à ausência de dados de secas anteriores. O ano de 2011 foi incluído porque foi chuvoso e pelo interesse em fazer um comparativo entre 2011 (ano chuvoso) e 2012-2014 (anos secos).

\section{RESULTADOS E DISCUSSÃO}

O IPP na escala de 3 meses identificou cinco secas, quatro severas e uma extrema. As durações das severas variaram de 1 a 8 meses, merecendo destaque a mais longa ( 8 meses) por ter acontecido recentemente (setembro de 2012 até abril de 2013). Esta reduziu drasticamente a produção das culturas. Durante esse período as famílias ficaram com a alimentação limitada em quantidade e qualidade, e a dieta das famílias mais vulneráveis ficou reduzida 
principalmente ao milho e feijão. A seca extrema ocorreu entre abril e setembro de 1998, durou 6 meses e atingiu o IPP médio de - 2,19, sendo outra seca que causou muitos impactos negativos na zona urbana e rural do município (Tabela 2A).

Com relação ao IPP na escala de 6 meses, mais uma vez a seca de 1998 se destaca, tendo início em abril de 1998 e término em dezembro do mesmo ano, com duração de 9 meses, IPP médio de - 2,11 e classificação extrema, a única nesta categoria. Outra seca que se destacou foi a de 2012-2013, pois apresentou a maior duração (12 meses). É importante observar as secas que foram identificadas pelas escalas anteriores e persistem nas demais, isso indica que elas merecem destaque maior, pois permaneceram atuando por mais tempo. As demais secas severas ocorreram entre fevereiro e março de 1970, fevereiro e maio de 1971, agosto de 1980 e janeiro de 1981 e outubro de 1981 e janeiro de 1982. Os IPPs médios destas secas variaram de - 1,53 até - 1,90 (Tabela 2B).

A quantidade de secas identificadas foi reduzida na escala de 9 meses, porém houve aumento na duração. Nessa escala foram identificadas cinco secas, três severas e duas extremas. As severas aconteceram entre 1980-1981, 1983-1984 e 2012-2013, todas estas atingiram o semiárido nordestino, em alguns lugares duraram mais tempo e causaram mais impactos negativos, em outros foram de menor intensidade. Já as secas extremas atuaram de janeiro a fevereiro de 1982, com duração de 2 meses e IPP médio de - 2,28. Com relação à outra seca extrema, novamente ela se repetiu, iniciando em março de 1998 e terminando em março de 1999 (Tabela 2C). É possível observar um aumento da duração desta seca se comparada com as das escalas anteriores, a categoria de seca extrema se manteve para os IPPs de 3, 6 e 9 meses.

Com o IPP na escala de 12 meses foram identificadas duas secas, ambas severas, uma entre 1998-2000 e a outra durante 2012-2013. A primeira teve duração de 21 meses e atingiu o IPP médio de - 1,81; a segunda durou 10 meses, com IPP médio de - 1,55. Resultados próximos a estes foram obtidos para a escala de 24 meses, duas secas identificadas, uma severa (maio de 1980 a fevereiro de 1981) e a outra extrema (fevereiro de 1999 a junho de 2000) e tiveram durações de 10 e 17 meses, respectivamente (Tabela 2D e E). Quando se aumentou a escala, muitas secas identificadas pelos IPPs anteriores foram agrupadas em escalas maiores, por exemplo, secas dos IPPs de 3, 6 e 9 meses se agruparam e formaram secas nos IPPs de 12 e 24 meses, quando isso acontece, deve-se dar maior importância as secas que permanecem nas escalas maiores.

As secas mais graves no município de Boqueirão ocorreram nos anos de 1980-1982, 19982000 e 2012-2013. Destas, a mais impactante foi a de 1998, isso ocorreu devido a um forte El Niño, que é considerado um dos mais intensos dos últimos 100 anos. Em anos de El Niño, quando as águas superficiais da bacia do Pacífico estão mais aquecidas que o normal, pode haver inibição da formação de nuvens e, consequentemente, diminuição das chuvas, principalmente na Região Norte do Nordeste. Além dos outros impactos, essa seca reduziu drasticamente a produção agropecuária e o abastecimento de água da região.

Com a escassez de chuvas nos municípios a montante do açude Epitácio Pessoa durante 1998-2000, o manancial não foi reabastecido. Isso fez com que fosse adotado o racionamento de água nos anos de 1998, 1999 e 2001, começando quando o açude tinha um volume próximo de 100.000.000 de $\mathrm{m}^{3}$ de água. Este foi um período crítico, haja vista que suas águas abastecem diversos municípios, entre eles, Campina Grande. A situação foi ainda mais agravada devido à irrigação no entorno do açude, pois esta é a atividade que consome mais água. Mesmo com a proibição pelo poder público, ela continuou sendo realizada de forma clandestina. 
Tabela 2. Quantidade, período, duração, IPP médio e categoria de secas obtidas pelos IPPs de $3,6,9,12$ e 24 meses para o município de Boqueirão-PB.

\begin{tabular}{cllccl}
\hline \multicolumn{5}{c}{ Escala de 3 meses (A) } \\
\hline Quantidade & \multicolumn{1}{c}{ Início } & \multicolumn{1}{c}{ Fim } & $\begin{array}{c}\text { Duração } \\
\text { (meses) }\end{array}$ & $\begin{array}{c}\text { IPP } \\
\text { médio }\end{array}$ & Categoria \\
\hline 1 & dezembro 1970 & março 1971 & 4 & $-1,55$ & Seca severa \\
2 & abril 1998 & setembro 1998 & 6 & $-2,19$ & Seca extrema \\
3 & janeiro 2005 & janeiro 2005 & 1 & $-1,67$ & Seca severa \\
4 & maio 2012 & julho 2012 & 3 & $-1,69$ & Seca severa \\
5 & setembro 2012 & abril 2013 & 8 & $-1,60$ & Seca severa \\
\hline
\end{tabular}

Escala de 6 meses $(\mathbf{B})$

\begin{tabular}{cllccl}
\hline Quantidade & \multicolumn{1}{c}{ Início } & \multicolumn{1}{c}{ Fim } & $\begin{array}{c}\text { Duração } \\
\text { (meses) }\end{array}$ & $\begin{array}{c}\text { IPP } \\
\text { médio }\end{array}$ & Categoria \\
\hline 1 & fevereiro 1970 & março 1970 & 2 & $-1,59$ & Seca severa \\
2 & fevereiro 1971 & maio 1971 & 4 & $-1,53$ & Seca severa \\
3 & agosto 1980 & janeiro 1981 & 6 & $-1,62$ & Seca severa \\
4 & outubro 1981 & janeiro 1982 & 4 & $-1,90$ & Seca severa \\
5 & abril 1998 & dezembro 1998 & 9 & $-2,11$ & Seca extrema \\
6 & agosto 2012 & julho 2013 & 12 & $-1,55$ & Seca severa \\
\hline
\end{tabular}

Escala de 9 meses $(\mathbf{C})$

\begin{tabular}{cllccl}
\hline Quantidade & \multicolumn{1}{c}{ Início } & \multicolumn{1}{c}{ Fim } & $\begin{array}{c}\text { Duração } \\
\text { (meses) }\end{array}$ & $\begin{array}{c}\text { IPP } \\
\text { médio }\end{array}$ & Categoria \\
\hline 1 & agosto 1980 & janeiro 1981 & 6 & $-1,60$ & Seca severa \\
2 & janeiro 1982 & fevereiro 1982 & 2 & $-2,28$ & Seca extrema \\
3 & dezembro 1983 & fevereiro 1984 & 3 & $-1,56$ & Seca severa \\
4 & março 1998 & março 1999 & 13 & $-2,00$ & Seca extrema \\
5 & novembro 2012 & junho 2013 & 8 & $-1,68$ & Seca severa \\
\hline
\end{tabular}

Escala de 12 meses (D)

\begin{tabular}{cccccc}
\hline Quantidade & Início & Fim & $\begin{array}{c}\text { Duração } \\
\text { (meses) }\end{array}$ & $\begin{array}{c}\text { IPP } \\
\text { médio }\end{array}$ & Categoria \\
\hline 1 & maio 1998 & janeiro 2000 & 21 & $-1,81$ & Seca severa \\
2 & dezembro 2012 & setembro 2013 & 10 & $-1,55$ & Seca severa \\
\hline Quantidade & Início & Escala de 24 meses (E) & & \\
\hline 1 & maio 1980 & Fim & $\begin{array}{c}\text { Duração } \\
\text { (meses) }\end{array}$ & $\begin{array}{c}\text { IPP } \\
\text { médio }\end{array}$ & Categoria \\
\hline 2 & fevereiro 1999 & junho 2000 & 10 & $-1,80$ & Seca severa \\
& & & 17 & $-2,25$ & Seca extrema \\
\hline
\end{tabular}

A seca de 2012-2016 tem causado muitos impactos à população que depende das águas do Epitácio Pessoa. Com precipitações abaixo da média nas bacias hidrográficas do Alto Paraíba e Taperoá durante esses anos, o volume vem sendo reduzido dia após dia. Atualmente (dezembro de 2016) o açude está com 5\% de sua capacidade. E mais uma vez o racionamento 
se fez presente, tendo início em dezembro de 2014, passando por 2015 e 2016. Inclusive, se não houver recarga brevemente, a tendência é de que o sistema seja desligado nos próximos 2, 3 meses, deixando diversas cidades sem água.

Pode ser observado na Figura 2 A, B, C, D e E que a correlação entre precipitação (mm) e área plantada (ha), área colhida (ha), quantidade produzida (ton), rendimento médio ( $\mathrm{kg} / \mathrm{ha}$ ) e valor da produção $(\mathrm{R} \$)$ da banana, caju, coco, goiaba, laranja, limão, mamão, maracujá e manga, que são culturas permanentes, nem sempre ocorre. Isso é explicado porque grande parte dessas culturas são irrigadas com a água do açude Epitácio Pessoa. Ou seja, quando aconteceu a seca, o manancial tinha uma satisfatória quantidade de água, o que fez com que os impactos nas culturas agrícolas permanentes não fossem tão intensos durante 2012-2013.

As maiores áreas plantadas e colhidas (ha) foram com banana, mamão e maracujá. Em 2011, 2012 e 2013 foram utilizados na plantação: 155, 155 e 200 ha; 25, 25 e 8 ha; e 8, 20 e 30 ha com banana, mamão e maracujá, respectivamente. Com relação à área colhida, foram obtidos os seguintes valores: banana, 155, 155 e 155 ha; mamão, 25, 25 e 8 ha; e maracujá, 8, 20 e 30 ha. É possível observar que mesmo com precipitação abaixo da média em 2012 e 2013, as culturas do mamão e maracujá tiveram toda a área que foi plantada, colhida (Figura 2 A e B). Isso foi possível por causa da irrigação.

Houve redução da quantidade produzida (ton) de banana, caju, coco, goiaba e manga durante 2012-2013. O contrário ocorreu com as demais culturas. Isso é explicado por que a bananeira, cajueiro, coqueiro, goiabeira e mangueira são mais tolerantes ao déficit hídrico, com isso, menos água foi ofertada a estas culturas e mais a laranjeira, limoeiro, mamoeiro e maracujazeiro (Figura $2 \mathrm{C}$ ).

Também houve redução do rendimento médio por hectare das culturas em função da seca. Reduções lineares durante os anos ocorreram para banana, caju, coco e goiaba. O rendimento médio em 2011, 2012 e 2013 foi, respectivamente, banana, $16.000,16.000$ e $11.613 \mathrm{~kg} / \mathrm{ha}$; caju, 400, 200 e $200 \mathrm{~kg} / \mathrm{ha}$; coco, 20.000, 8.000 e $5.100 \mathrm{~kg} / \mathrm{ha}$; e goiaba, $8.000,6.000$ e $5.200 \mathrm{~kg} / \mathrm{ha}$ (Figura 2 D). As outras culturas tiveram menores reduções em função do que já foi discutido nos parágrafos anteriores. Todas as culturas tiveram redução do valor da produção, exceto laranjeira e maracujazeiro. Os valores para estas culturas durante 2011, 2012 e 2013 foram: $18.000,30.000$ e $\mathrm{R} \$ 62.000 ; 56.000,180.000$ e $\mathrm{R} \$ 270.000$, respectivamente, (Figura $2 \mathrm{E}$ ). Isso ocorreu porque na falta de alguns produtos, houve aumento dos preços, o que se conhece por lei da oferta e da procura. Quando a oferta de produtos é maior que a procura, a tendência é de que ocorra a redução de preços. Já nos períodos em que a demanda passa a superar a oferta, a tendência é o aumento dos preços.

A seca em 2012 e 2013 impactou severamente as culturas agrícolas temporárias no município de Boqueirão. Pode ser observado na Figura 3 a correlação entre precipitação $(\mathrm{mm})$ e área plantada (ha), área colhida (ha), quantidade produzida (ton), rendimento médio ( $\mathrm{kg} / \mathrm{ha}$ ) e valor da produção $(\mathrm{R} \$)$.

Com exceção da batata-doce, todas as outras culturas tiveram redução de área plantada (ha) em 2012 e 2013. A maior ocorreu com as culturas de feijão e milho, isso causou impactos gravíssimos, pois são alimentos que garantem a subsistência da população. Já a batata-doce não teve redução de área plantada porque a cultura era cultivada nas vazantes dos açudes, principalmente do Epitácio Pessoa, (Figura 3 A).

A área colhida está diretamente relacionada com a plantada. A redução da área plantada em 2012 e 2013 resultou em menor área colhida. Batata-doce, cebola e tomate tiveram toda a área que foi plantada, colhida. O oposto aconteceu com algodão herbáceo, fava, feijão e milho. Para estas culturas as áreas colhidas em 2011, 2012 e 2013 foram: algodão herbáceo, 20, 0 e 0 ha; fava, 100, 0 e 10 ha; feijão, 700, 0 e 40 ha; e milho, 1.000, 100 e 20 ha, respectivamente, (Figura 3 B). 


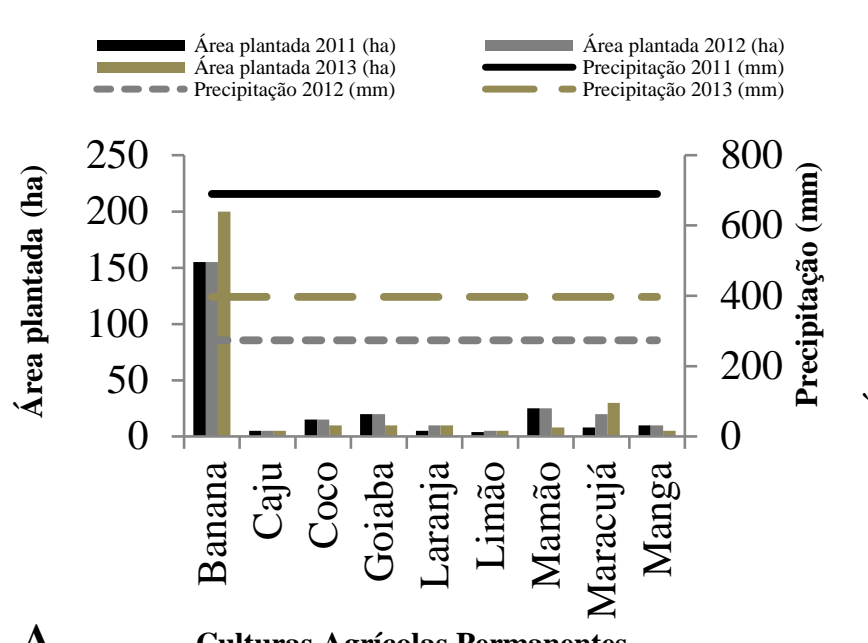

A Culturas Agrícolas Permanentes

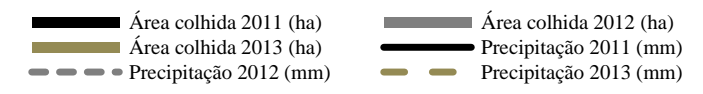

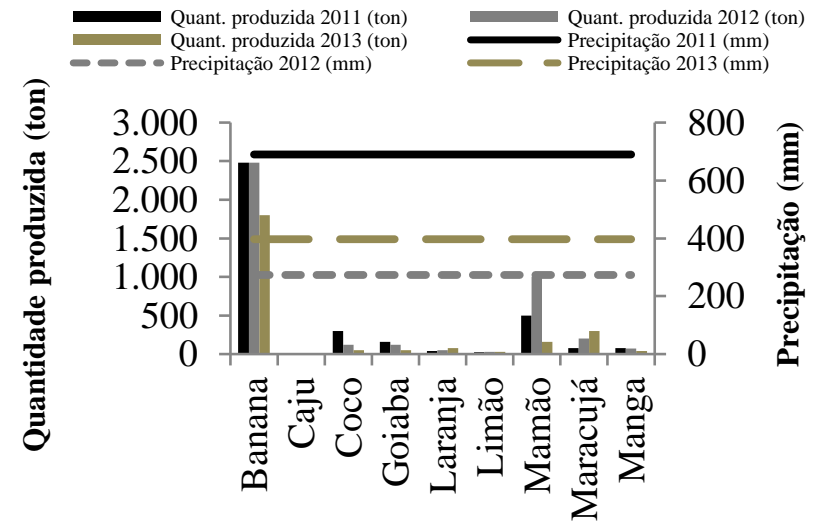

Culturas Agrícolas Permanentes

C

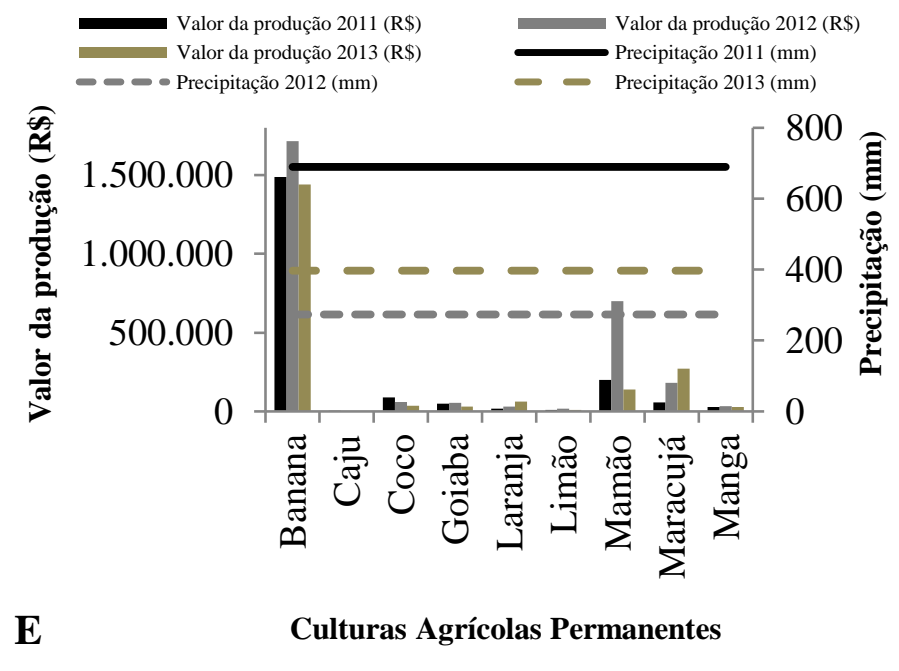

Figura 2. Impactos da seca de 2012-2013 na área plantada (ha) (A), área colhida (ha) (B), quantidade produzida (ton) $(\mathrm{C})$, rendimento médio $(\mathrm{kg} / \mathrm{ha})(\mathrm{D})$ e valor da produção $(\mathrm{R} \$)(\mathrm{E})$ das culturas agrícolas permanentes no município de Boqueirão-PB.

A quantidade produzida (ton) teve grande redução. Os valores foram os seguintes em 2011, 2012 e 2013: algodão herbáceo, 16, 0 e 0 ton; cebola, 2.000, 4.800 e 1.000 ton; fava, 30, 0 e

Rev. Ambient. Água vol. 12 n. 2 Taubaté - Mar. / Apr. 2017 
1 ton; feijão, 280, 0 e 6 ton; milho, 600, 12 e 5 ton; e tomate, 3.200, 5.250 e 2.800 ton, respectivamente, (Figura 3 C). A redução para valores próximos de 0 ton em 2012 e 2013 nas culturas de algodão, fava, feijão e milho é devido as mesmas serem totalmente dependentes das chuvas que caem durante janeiro-maio de cada ano.
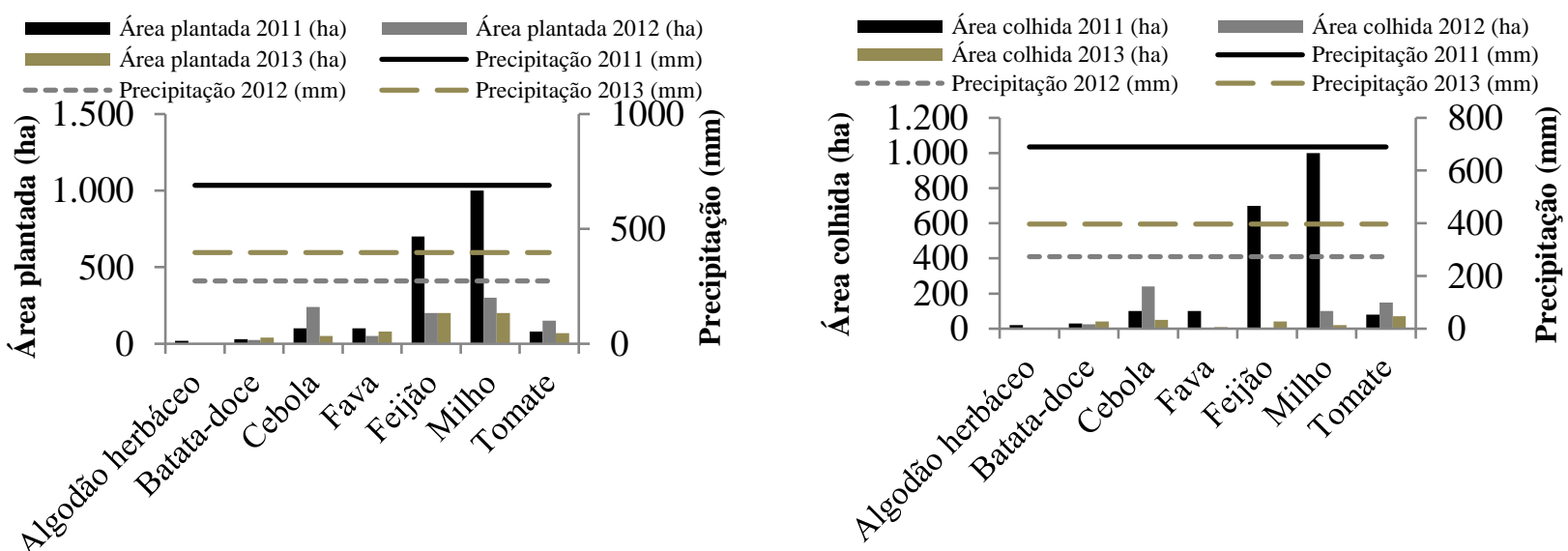

Culturas Agrícolas Temporárias

Culturas Agrícolas Temporárias

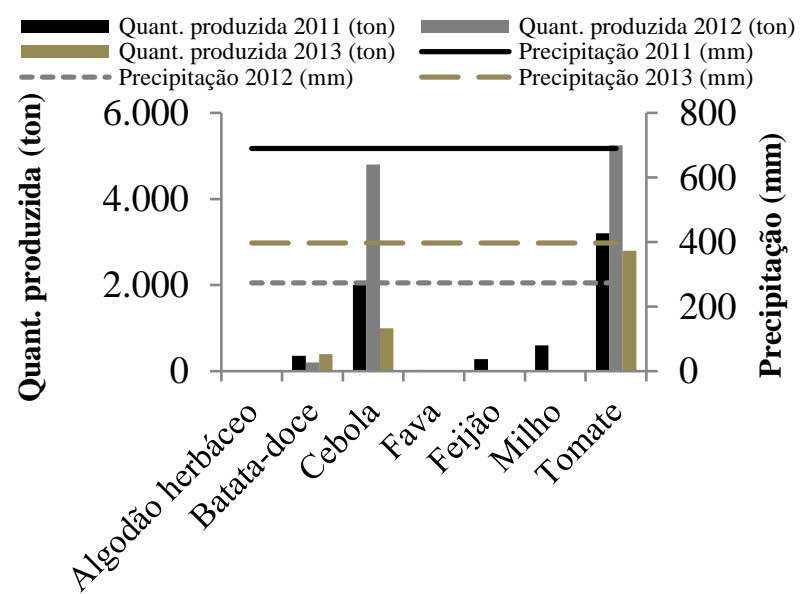

Culturas Agrícolas Temporárias

C

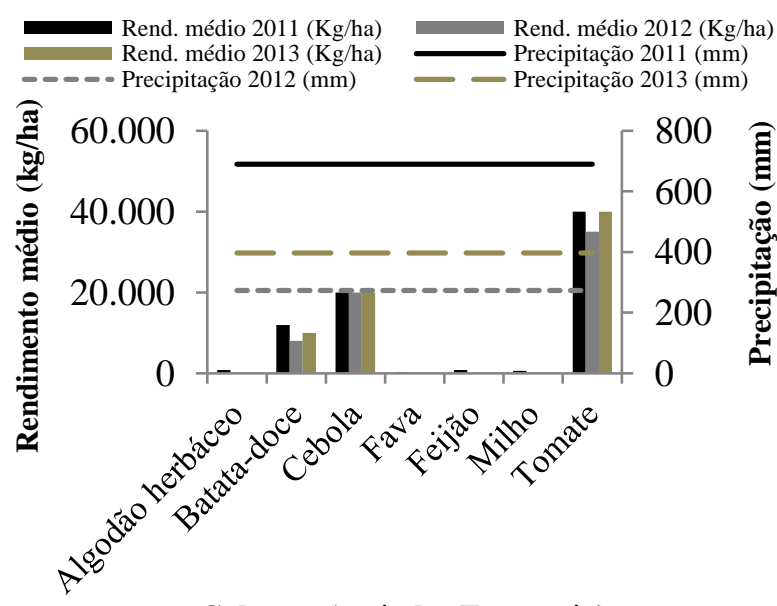

Culturas Agrícolas Temporárias

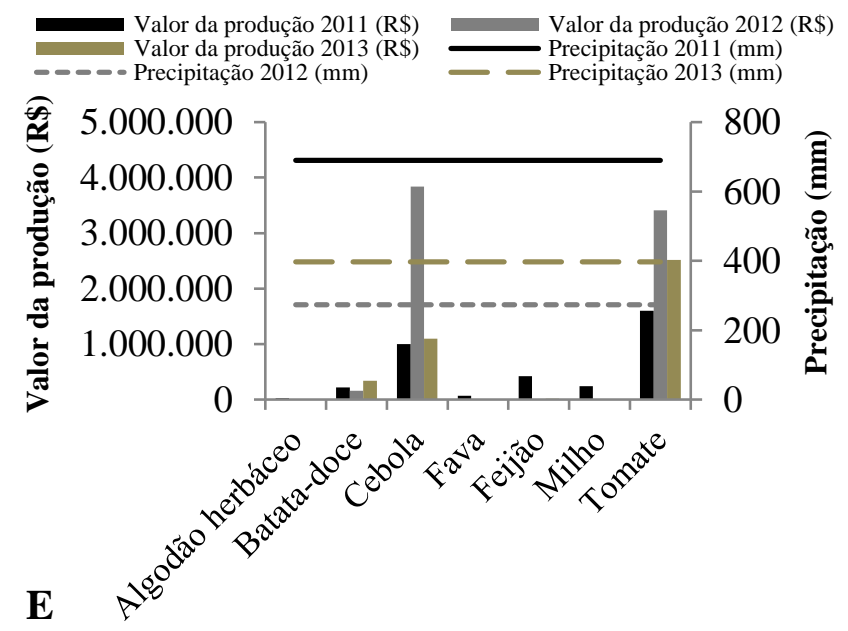

Culturas Agrícolas Temporárias

Figura 3. Impactos da seca de 2012-2013 na área plantada (ha) (A), área colhida (ha) (B), quantidade produzida (ton) $(\mathrm{C})$, rendimento médio $(\mathrm{kg} / \mathrm{ha})(\mathrm{D})$ e valor da produção $(\mathrm{R} \$)(\mathrm{E})$ das culturas agrícolas temporárias no município de Boqueirão-PB. 
Houve redução do rendimento médio por hectare das culturas em função da seca. $\mathrm{O}$ algodão herbáceo e a fava não produziram nenhum $\mathrm{kg} / \mathrm{ha}$ durante $2012 \mathrm{e} 2013$. A maior redução ocorreu com algodão herbáceo, batata-doce, fava, feijão e milho (Figura 3 D). A Figura 3 E evidencia a redução do valor da produção entre 2011, 2012 e 2013. Os valores foram os seguintes: algodão herbáceo, 24.000, 0 e R\$ 0; batata-doce, 216.000, 160.000 e R \$340.000; cebola, 1.000.000, 3.840.000 e R\$ 1.100.000; fava, 66.000, 0 e R\$ 5.000; feijão, 424.000, 0 e $\mathrm{R} \$$ 13.000; milho, 240.000, 8.000 e R \$ 4.000; e tomate, 1.600.000, 3.413.000 e R\$ 2.520.000. Esse é o tamanho do impacto econômico e social que as famílias tiveram.

Ocorreu redução do efetivo de animais durante a seca, principalmente em 2012 e 2013. Com a precipitação próxima da média em 2014, a quantidade de animais voltou a ter valores próximos ou superiores aos de 2011.

A menor redução ocorreu com os asininos, equinos e muares. Isso porque a quantidade desses animais era pequena e a maioria dos criadores utilizavam para realizar atividades no meio rural, assim não podiam se desfazer dos mesmos.

A quantidade de aves domésticas (galos e galinhas) e suínos foi reduzida entre os dois primeiros anos, havendo aumento no terceiro e quarto. Os números em 2011, 2012, 2013 e 2014 foram os seguintes: galos e galinhas, 13.900, 13.400, 18.050 e 19.000 animais; e suínos, 750, 725, 987 e 1.400 animais, respectivamente, (Figura 4). O aumento da quantidade de galos, galinhas e suínos mesmo durante os anos secos de 2013 e 2014 é muito importante, pois esses animais contribuem bastante para a alimentação e economia das famílias.

Os bovinos apresentaram o segundo maior rebanho, seguido por caprinos e ovinos. A quantidade de bovinos, caprinos e ovinos criados em 2011, 2012, 2013 e 2014 foi de 10.200, 8.800, 8.894 e 10.000 animais; 9.088, 6.500, 8.040 e 9.000 animais; e 3.660, 3.000, 4.831 e 7.000 animais, respectivamente, (Figura 4). Com a redução de água e alimento durante a seca, alguns animais foram vendidos por preços abaixo do valor de mercado, outros morreram de fome e sede. A maior quantidade de bovinos em relação aos caprinos e ovinos é devido o município ser uma bacia leiteira de grande importância, com várias associações e cooperativas de beneficiamento do leite de vaca. Também se destaca na pecuária de corte. Já o grande número de caprinos e ovinos é por causa de sua adaptabilidade às condições adversas do semiárido e facilidade na comercialização.

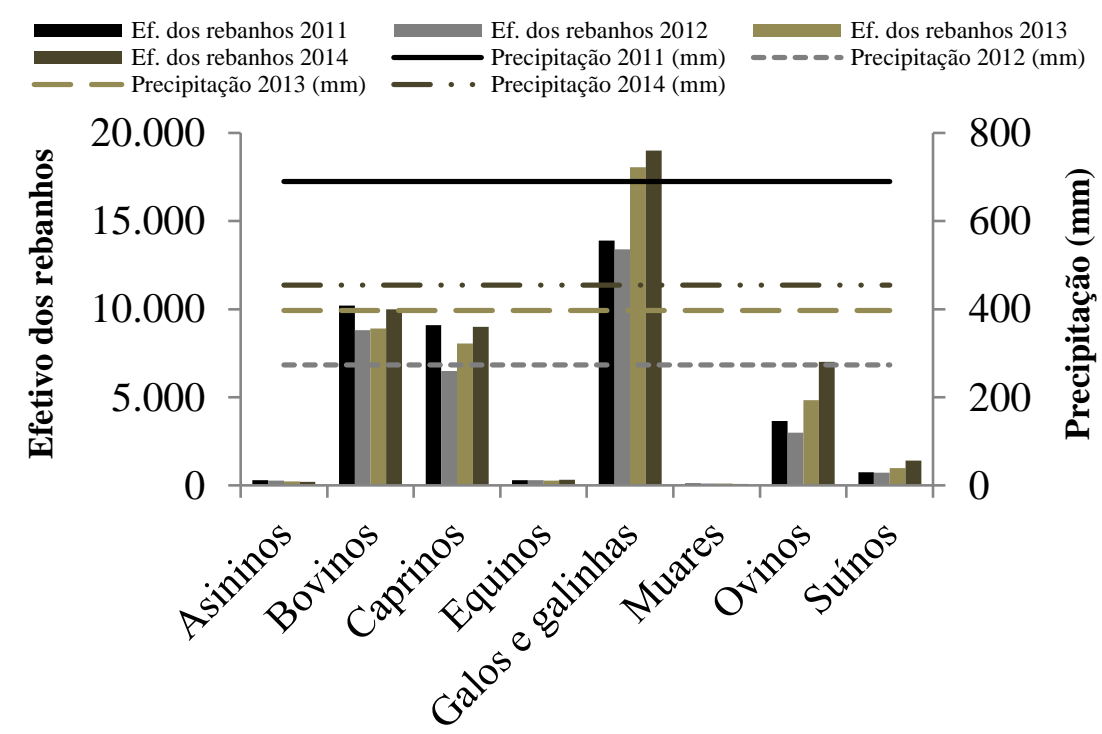

\section{Rebanhos}

Figura 4. Impactos da seca de 2012-2014 no efetivo dos rebanhos no município de Boqueirão-PB. 
A seca em 2012 dificultou o desenvolvimento das pastagens, influenciou fortemente o efetivo do rebanho bovino, causando redução na produção do leite. Com a diminuição de bovinos em 2012, a quantidade de leite produzido reduziu, passando de 2.808 .000 litros em 2011 para 2.600.000 em 2012. Mesmo com a seca em 2013 e 2014, houve aumento da quantidade de leite produzido em relação ao ano de 2011, isso ocorreu em função da compra de farelo de trigo, milho e algodão para alimentar os animais (Figura $5 \mathrm{~A}$ ).

A seca reduziu a quantidade de ovos produzidos. A produção de ovos em 2011 foi de 24.000 dúzias, 22.000 em 2012, 23.000 em 2013 e 23.000 em 2014 (Figura 5 B). Além da redução das espécies vegetais, a pequena produção de milho nas propriedades em função da falta de chuva reduziu a produção das galinhas. A redução da quantidade de ovos ocorreu mesmo com o programa de subsidio de milho da CONAB, onde os criadores podiam comprar a saca de 60 quilos pelo preço de $\mathrm{R} \$ 18,10$ em 2012. Só que houve aumento nos valores do milho comercializado em 2013 e 2014, inviabilizando a compra.

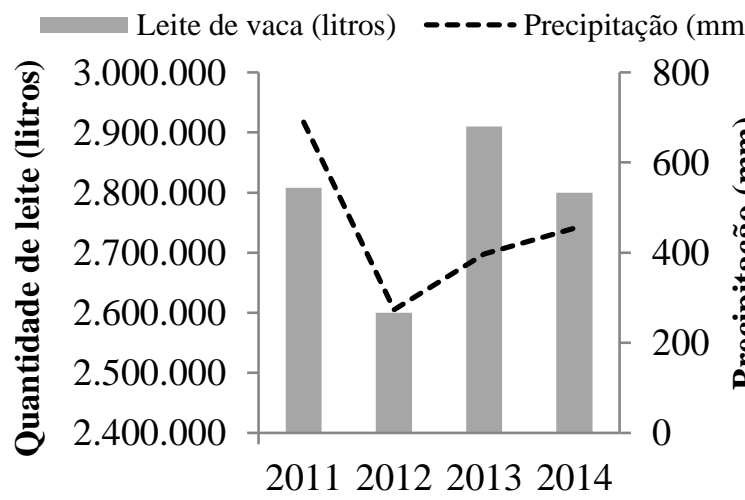

A

Anos

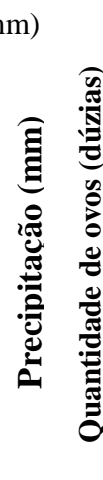

B

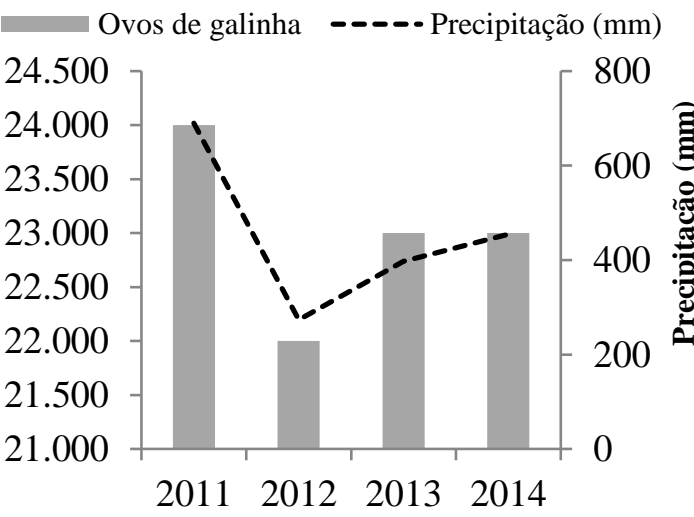

Anos

Figura 5. Impactos da seca de 2012-2014 na quantidade de leite de vaca (A) e de ovos de galinha (B) no município de Boqueirão-PB.

A diminuição das chuvas e da quantidade de leite e ovos produzidos em 2012, 2013 e 2014 provocou aumento do valor obtido com a venda de leite e ovos, e isso está diretamente relacionado com a lei da oferta e da procura, (Figura 6 A e B).

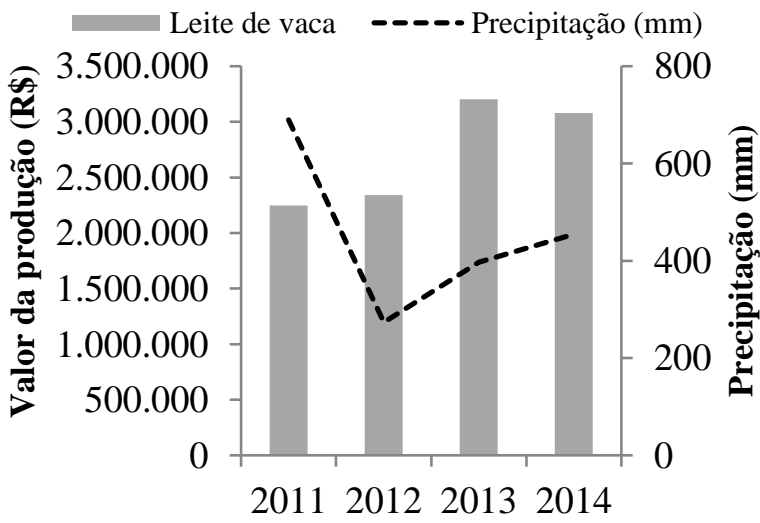

A

Anos

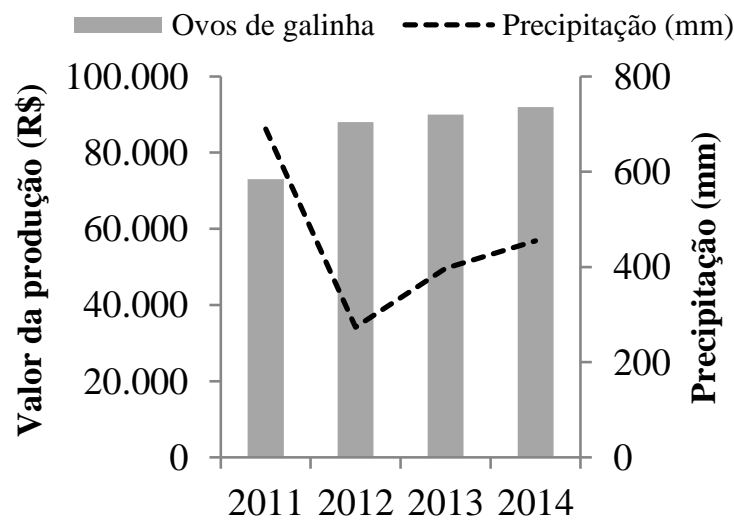

B

Anos

Figura 6. Impactos da seca de 2012-2014 no valor da produção do leite de vaca (A) e de ovos de galinha (B) no município de Boqueirão-PB. 


\section{CONCLUSÕES}

As secas mais graves no município de Boqueirão ocorreram nos anos de 1980-1982, 1998-2000 e 2012-2013. Destas, a mais impactante foi a de 1998-2000. Além de muitos outros impactos, essa seca reduziu drasticamente a produção agropecuária e o abastecimento de água da região.

Os impactos mais intensos durante a seca 2012-2014 ocorreram em 2012 e 2013. As culturas agrícolas temporárias foram mais impactadas do que as permanentes. Isso ocorreu porque a maioria das permanentes eram irrigadas, diferente das temporárias. A maior redução de animais também ocorreu durante 2012 e 2013, com uma relação direta entre precipitação e efetivo dos rebanhos. Não houve redução do valor da produção em função das secas.

Para redução dos impactos que ocorreram, é necessário aumentar o número de cisternas, principalmente a calçadão. É necessário também perfurar poços e construir açudes, além de fazer manutenção nos que estejam com capacidade reduzida ou desativados, construir barragens subterrâneas e tanques naturais, terminar e colocar em funcionamento a transposição do Rio São Francisco, incentivar a gestão dos recursos hídricos, criar programas que visem o fortalecimento da agricultura familiar, incentivando a fenação, silagem na criação animal e fomentar o plantio de culturas adaptadas à região.

\section{REFERÊNCIAS}

ABRAMOWITZ, M.; STEGUN, I. A. (Eds.). Handbook of Mathematical Functions with formulas, graphs, and mathematical tables. New York: Dover Publications, 1965. $1046 \mathrm{p}$.

BORDI, I.; FRAEDRICH, F.; SUTERA, A. Observed drought and wetness trends in Europe: an update. Hydrology and Earth System Sciences, v. 13, p. 1519-1530, 2009. http://dx.doi.org/10.5194/hess-13-1519-2009.

BRASIL. As secas do Nordeste: uma abordagem histórica de causas e efeitos. Recife: SUDENE, 1981.

FARIAS, A. A.; SOUZA, J. T. A.; SOUSA, F. A. S. Identificação e análise de secas severas e extremas no município de Taperoá-PB. Revista Brasileira de Geografia Física, v. 07, n. 05, p. 818-826, 2014.

FISCHER, T.; GEMMER, M.; SU, B.; SCHOLTEN, T. Hydrological long-term dry and wet periods in the Xijiang River basin, South China. Hydrology and Earth System Sciences, v. 17, p. 135-148, 2013. http://dx.doi.org/10.5194/hess-17-135-2013

GUTTMAN, N. Accepting the standardised precipitation index: a calculation algorithm. Journal of the American Water Resources Association, v. 35, p. 311-322, 1999. http://dx.doi.org/10.1111/j.1752-1688.1999.tb03592.x

HAYES, M. J.; SVOBODA, M. D.; MURO, N. A.; WIDHALM, M. The Lincoln declaration on drought indices: universal meteorological drought index recommended. Bulletin of the American Meteorological Society, v. 92, p. 485-488, 2011. http://dx.doi.org/10.1175/2010BAMS3103.1.

INSTITUTO BRASILEIRO DE GEOGRAFIA E ESTATÍSTICA - (IBGE). Produção agrícola e pecuária municipal. 2015. Disponível em: https://goo.gl/jRKqfy. Acesso em: 13 out. 2015. 
KEYANTASH, J.; DRACUP, J. A. The quantification of drought: an evaluation of drought indices. Bulletin of the American Meteorological Society, v. 83, p. 1167-1180, 2002. http://dx.doi.org/10.1175/1520-0477(2002)083\%3C1191:TQODAE\%3E2.3.CO;2

LI, B.; RODELL, M. Evaluation of a model-based groundwater drought indicator in the conterminous U. S. Journal of Hydrology, v. 526, p. 78-88, 2015. http://dx.doi.org/10.1016/j.jhydrol.2014.09.027.

LIVADA, I.; ASSIMAKOPOULOS, V. D. Spatial and temporal analysis of drought in Greece using the Standardized Precipitation Index (SPI). Theoretical and Applied Climatology, v. 89, p. 143-153, 2007. http://dx.doi.org/;10.1007/s00704-005-0227-z.

LLOYD-HUGES, B.; SAUNDERS, M. A drought climatology for Europe. International Journal of Climatology, v. 22, p. 1571-1592, 2002. http://dx.doi.org/10.1002/joc.846

MCKEE, T. B.; DOESKEN, N. J.; KLEIST, J. The relationship of drought frequency and duration of time scales. In: CONFERENCE ON APPLIED CLIMATOLOGY, 8, 1993, Boston. Proceedings... Boston: American Meteorological Society, 1993. p. 179-183.

MISHRA, A. K.; SINGH, V. P. A review of drought concepts. Journal of Hydrology, v. 391, p. 202-216, 2010. http://dx.doi.org/10.1016/j.jhydrol.2010.07.012.

SANTOS, J. F.; PULIDO-CALVO, I.; PORTELA, M. M. Spatial and temporal variability of droughts in Portugal. Water Resources Research, v. 46, 2010. http://dx.doi.org/10,1029/2009WR008071

SIRDAS, S.; SEN, Z. Spatio-temporal drought analysis in the Trakya region, Turkey.

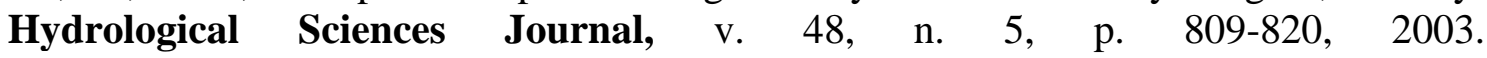
http://dx.doi.org/10.1623/hysj.48.5.809.51458

SONMEZ, F.; KOMUSCU, A.; ERKAN, A.; TURGU, E. An analysis of spatial and temporal dimension of drought vulnerability in turkey using the standardized precipitation index. Natural Hazards, v. 35, p. 243-264, 2005.

TEIXEIRA, C. F. A.; DAMÉ, R. C. F.; BACELAR, L. C. S.; SILVA, G. M.; COUTO, R. S. Intensidade da seca utilizando índices de precipitação. Revista Ambiente e Água, v. 8, n. 3, 2013. http://dx.doi.org/10.4136/ambi-agua.1245

UNITED NATIONS CONVENTION TO COMBAT DROUGHT AND DESERTIFICATION - UNCCD. United Nations Convention to Combat Drought and Desertification in Countries Experiencing Serious Droughts and/or Desertification. Particularly in Africa. Paris, 1994.

VICENTE-SERRANO, S. Spatial and temporal analysis of droughts in the Iberian Peninsula (1910-2000). Hydrological Sciences Journal, v. 51, p. 83-97, 2006. http://dx.doi.org/10.1623/hysj.51.1.83

WILHITE, D. A.; SVOBODA, M. D.; HAYES, M. J. Understanding the complex impacts of drought: A key to improving drought mitigation and preparedness. Water Resources Management, v. 21, n. 5, p. 763-774, 2007. http://dx.doi.org/10.1007/s11269-006-90765

WORLD METEOROLOGICAL ORGANIZATION - WMO. Report on Drought and Countries Affected by Drought During 1974-1985. Geneva, 1986. 118p. 
ZHAI, J.; SU, B.; KRYSANOVA, V.; VETTER, T.; GAO, C.; JIANG, T. Spatial variation and trends in PDSI and SPI indices and their relation to streamflow in 10 large regions of $\begin{array}{lllllll}\text { China. Journal of Climate, v. 23, p. 649-663, } 2010 . & \end{array}$ http://dx.doi.org/10.1175/2009JCLI2968.1 